\title{
Total Quantification of Magnesium Alloys by X-ray Fluorescence Spectrometry Using the "Standardless" Fundamental Parameter Method
}

\author{
Wataru Matsuda, ${ }^{* \dagger}$ Atsushi Morikawa, ${ }^{*}$ Atsushi Ohbuchi,* Takao Moriyama, ${ }^{*}$ and \\ Toshihiro NAKAMURA*,**
}

*Rigaku Corporation, 14-8 Akaoji-cho, Takatsuki, Osaka 569-1146, Japan

**Meiji University, 1-1 Kanda-Surugadai, Chiyoda, Tokyo 101-8301, Japan

\begin{abstract}
X-ray fluorescence spectrometry using the "standardless" fundamental parameter method has been studied for the whole elemental analysis of magnesium alloys. Twelve major elements were determined: $\mathrm{Mg}, \mathrm{Al}, \mathrm{Si}, \mathrm{Ca}, \mathrm{Mn}, \mathrm{Fe}, \mathrm{Ni}, \mathrm{Cu}, \mathrm{Zn}$, $\mathrm{Ag}, \mathrm{Sn}$ and $\mathrm{Pb}$. The specimens used were over $30 \mathrm{~mm}$ in diameter and greater than $10 \mathrm{~mm}$ thick to determine $\mathrm{Sn} K \alpha$ which has the largest analyzing depth $(9 \mathrm{~mm})$ through the alloy samples. The surfaces of the specimens were polished with fine alumina abrasive paper (\#240) to remove the oxide layer and to avoid the influence of any surface roughness variation on the intensities of $\mathrm{Mg} K \alpha, \mathrm{Al} K \alpha$ and $\mathrm{Si} K \alpha$ which have smaller analyzing depths. The total quantitative values of the 12 elements, determined by the FP calculation, were normalized to 100 mass\%. The analytical values obtained by this method were comparable to those obtained by the conventional calibration curves method. The relative standard deviations were $6.6 \%$ for 0.0014 mass \% of $\mathrm{Ni}$, and $0.005 \%$ for 93.82 mass\% of $\mathrm{Mg}$ in AZ91 series $\mathrm{Mg}$ alloys. The validation results of the proposed method for 12 elements were successful for the five CRMs tested.
\end{abstract}

Keywords Magnesium alloys, X-ray fluorescence spectrometry, fundamental parameter method

(Received February 4, 2020; Accepted March 30, 2020; Advance Publication Released Online by J-STAGE April 3, 2020)

\section{Introduction}

Magnesium alloys are nowadays more widely used as metallic materials than aluminum alloys, because of their unique characteristics, such as low specific weight, high vibration damping, dent resistance, dimensional stability and ability to shield electromagnetic waves. Magnesium ingots are used not only as a base metal for magnesium alloys, but also as an additive to aluminum alloys. Magnesium alloys are used in a wide range of products, such as automobiles, aircrafts and railway parts, mobile electronics and acoustic devices. ${ }^{1}$ In Japan, all magnesium ingots are imported, and the annual demand for magnesium is 7000 tons for structural materials. ${ }^{2}$ Several elements are added to magnesium metals to create alloys with different characteristics. For example, $\mathrm{Al}$ and $\mathrm{Zn}$ are added to enhance the strength and castability, and $\mathrm{Ca}$ is added to improve the heat resistance. Rare-earth elements, such as Y, Gd, $\mathrm{La}$ and $\mathrm{Ce}$, may be added to achieve both heat resistance and mechanical strength. ${ }^{3}$ However, even trace amounts of $\mathrm{Fe}, \mathrm{Ni}$ and $\mathrm{Cu}$ can increase the corrosiveness, ${ }^{4,5}$ therefore, the composition of magnesium alloys must be strictly controlled. JIS standards (H1332 - 1345) documents specify the official analysis methods for magnesium ingots and magnesium alloys. ${ }^{6-20}$ These standards refer to gravimetric, ${ }^{7,20}$ and titration ${ }^{7,8}$ methods, absorption photometry, ${ }^{7,9-11,13,15}$ atomic absorption

† To whom correspondence should be addressed.

E-mail:w-matuda@rigaku.co.jp spectrophotometry, ${ }^{7-9,11-14,16}$ spark-discharge atomic emission spectrometry (SD-AES ${ }^{6}$ ) and inductively coupled plasma atomic emission spectrometry (ICP-AES ${ }^{14,17-20}$ ). These standards of methods require skilled experts because calibration curves must be created with a series of artificial standard solutions, and a set of reference materials that provide an identical matrix. In addition, because newly developed magnesium alloys contain different elements that have been added for further functionalization, the compositions of some commercialized magnesium alloys differ from those of the corresponding reference materials. ${ }^{21-23}$ That makes it difficult to create accurate calibration curves and, even if there is a demand for quantification, reference materials for the new elements may not exist. On the other hand, despite the growing need for analysis in various fields, there is a shortage of engineers with sufficient skills to perform the analysis. Therefore, there is an increasing demand for analytical methods that can obtain rapid, simple and accurate quantitative values without using reference materials.

$\mathrm{X}$-ray fluorescence (XRF) spectrometry is a highly versatile nondestructive analytical technique. XRF does not require highly skilled analysts to produce accurate results. Since XRF can be automated and conducted in a short time, it is widely used for quality control in various manufacturing industries, such as iron and steel ${ }^{24}$ and ceramics. ${ }^{25}$ As with other analytical methods, XRF values are commonly quantified using calibration curves. However, XRF has relatively simple excitation and absorption processes; therefore, fluorescent X-ray intensities can be calculated using fundamental parameters (FP). This method is called the fundamental parameter method 
Table 1 Measuring conditions of a wavelength-dispersive X-ray fluorescence spectrometer of Rigaku ZSX Primus IV

\begin{tabular}{|c|c|c|c|c|c|c|}
\hline & $\mathrm{Mg}$ & $\mathrm{Al}$ & $\mathrm{Si}$ & $\mathrm{Ca}$ & $\mathrm{Mn}$ & $\mathrm{Fe}$ \\
\hline Analytical line & $K \alpha$ & $K \alpha$ & $K \alpha$ & $K \alpha$ & $K \alpha$ & $K \alpha$ \\
\hline Tube voltage/kV & 50 & 50 & 50 & 50 & 50 & 50 \\
\hline Tube current $/ \mathrm{mA}$ & 60 & 60 & 60 & 60 & 60 & 60 \\
\hline Crystal & RX25 & PETH & PETH & $\operatorname{LiF}(200)$ & $\operatorname{LiF}(200)$ & $\operatorname{LiF}(200)$ \\
\hline Detector & F-PC & F-PC & F-PC & F-PC & $\mathrm{SC}$ & $\mathrm{SC}$ \\
\hline Peak counting time/s & 4 & 4 & 4 & 4 & 4 & 4 \\
\hline \multirow[t]{2}{*}{ BG counting time/s } & 2 (2 points) & 2 (2 points) & 2 (2 points) & 2 (2 points) & 2 (2 points) & 2 (2 points) \\
\hline & $\mathrm{Ni}$ & $\mathrm{Cu}$ & $\mathrm{Zn}$ & $\mathrm{Ag}$ & Sn & $\mathrm{Pb}$ \\
\hline Analytical line & $K \alpha$ & $K \alpha$ & $K \alpha$ & $K \alpha$ & $K \alpha$ & $L \beta_{1}$ \\
\hline Tube voltage/kV & 50 & 50 & 50 & 50 & 50 & 50 \\
\hline Tube current $/ \mathrm{mA}$ & 60 & 60 & 60 & 60 & 60 & 60 \\
\hline Crystal & $\mathrm{LiF}(200)$ & $\mathrm{LiF}(200)$ & $\mathrm{LiF}(200)$ & $\operatorname{LiF}(200)$ & $\mathrm{LiF}(200)$ & $\mathrm{LiF}(200)$ \\
\hline Detector & $\mathrm{SC}$ & $\mathrm{SC}$ & $\mathrm{SC}$ & $\mathrm{SC}$ & $\mathrm{SC}$ & $\mathrm{SC}$ \\
\hline Peak counting time/s & 4 & 4 & 4 & 4 & 4 & 4 \\
\hline BG counting time/s & 2 (2 points) & 2 (2 points) & 2 (2 points) & 2 (2 points) & 2 (2 points) & 2 (2 points) \\
\hline
\end{tabular}

RX25, synthetic multi layer film; PETH, pentaerythritol; F-PC, gas flow proportional counter; SC, scintillation counter; BG, background.

(FP method). ${ }^{26}$ The FP method can correct for absorption and excitation effects of fluorescent X-rays in samples; therefore, it is possible to quantify samples having different compositions. In such cases, one or more reference materials may be measured in advance, and the sensitivity coefficients registered in the spectrometer are corrected. When XRF spectrometers are used to measure compounds of high purity and known composition, such as pure metals and oxides, built-in sensitivity coefficients are converted from the measured intensity to theoretical intensity for all elements that can be analyzed. If these sensitivity coefficients are true, unknown samples can be quantified without type standards. This is known as the "standardless" FP method. In the case of powder samples, such as rocks, the X-ray intensity differs due to any non-uniformity of the sample, and may cause errors in the analytical values of the FP method. On the other hand, since metal samples, such as magnesium alloys, are assumed to have very little non-uniformity, the error in the analytical value of the FP method is considered to be small. To the best of our knowledge, no previous reports describe the analysis of magnesium ingots and alloys using the FP method.

In this study, to establish the determination of the 12 major elements in magnesium ingots or alloys without using reference materials, we investigated (1) the analytical depth of each quantitative element, (2) the possibility by the influence of oxide film formation on the X-ray fluorescence intensity and (3) the effect of surface polishing. After investigating these three topics and establishing analysis conditions, three types of samples (magnesium ingot, AZ91D and AM60B) were analyzed using the FP method, and the results were compared to the values from the conventional calibration curves method.

\section{Experimental}

Apparatus, instrumental conditions, and sample preparation

We used the ZSX Primus IV, a wavelength dispersive X-ray fluorescence spectrometer (Rigaku Co., Japan) that is equipped with a Rh end window-type X-ray tube operated at a voltage of $50 \mathrm{kV}$ with a tube current of $60 \mathrm{~mA}$. Measurements were performed in a vacuum. Other measurement conditions are listed in Table 1. The measurement time was approximately 5 min per sample. The sample was polished using X871KN abrasive (alumina \#240, less than $40 \mu \mathrm{m}$ in roughness) manufactured by Noritake Coated Abrasive Co, Ltd.

\section{Samples and reference materials}

Three unknown samples were used in this study, assigned labels Mg-A (magnesium ingots), Mg-B (AZ91D alloys) and Mg-C (AM60B alloys). The diameters of the specimens used were $30 \mathrm{~mm}$ or larger and $10 \mathrm{~mm}$ or thicker. The exposed surfaces of the specimens were belt-polished with alumina abrasive paper for $30 \mathrm{~s}$ according to JIS H1322. ${ }^{6}$ After polishing, they were immediately measured by XRF. To validate the quantitative results, five certified reference materials were used (MBH Analytical 61X MGP2 (magnesium ingot), 61X MGP6 (magnesium ingot), 65XMGA15 (Mg-Al-Zn alloys), 65XMGA16 (Mg-Al-Zn alloys), and 65XMGA21 (AZ125A alloys)). The CRMs' values are listed in Table 2.

\section{Quantification using FP method}

For quantification using the FP method, the pre-installed sensitivity coefficients were used. Setting up the pre-installed sensitivity coefficients does not use CRMs, such as magnesium alloys. These sensitivity coefficients were determined by measuring known compositions, such as pure metals $(\mathrm{Mg}, \mathrm{Al}$, $\mathrm{Fe}$ etc.), and several stoichiometric components. Twelve elements were analyzed: $\mathrm{Mg}$ as the main component with four alloy elements ( $\mathrm{Al}, \mathrm{Ca}, \mathrm{Mn}, \mathrm{Zn}$ ), three functional interference elements $(\mathrm{Fe}, \mathrm{Ni}, \mathrm{Cu})$ and four other elements $(\mathrm{Si}, \mathrm{Ag}, \mathrm{Sn}, \mathrm{Pb})$. The quantitative values were calculated by normalizing the sum of all concentrations to 100 mass $\%$.

Although the samples can contain trace amounts of hydrogen and oxygen, the concentrations of these elements in magnesium alloys are extremely low and negligible. Therefore, the normalization calculation excluded hydrogen and oxygen concentrations.

\section{Quantification using calibration curves}

Calibration curves for the 12 elements specified in above section "Quantification using FP method" were certified to compare the quantitative results with those of the FP method. Five certified materials (indicated in above section "Samples and reference materials") were used for the calibration curves. By using the resulting calibration curves, three unknown 
Table 2 Certified reference materials (CRMs) of magnesium alloys issued by MBH Analytical Ltd (unit: mass\%)

\begin{tabular}{lcccccc}
\hline \multicolumn{1}{c}{ CRM } & $\mathrm{Mg}^{\mathrm{a}}$ & $\mathrm{Al}$ & $\mathrm{Si}$ & $\mathrm{Ca}$ & $\mathrm{Mn}$ & $\mathrm{Fe}$ \\
\hline 61XMGP2 & 99.82 & 0.065 & 0.029 & 0.0139 & 0.0118 & 0.0061 \\
61XMGP6 & 99.75 & 0.0449 & 0.044 & - & 0.0125 & 0.0041 \\
65XMGA15 & 88.78 & 10.67 & 0.034 & - & 0.067 & 0.01 \\
65XMGA16 & 88.69 & 6.78 & 0.023 & 0.0024 & 0.271 & 0.0073 \\
65XMGA21 & 82.39 & 12.37 & 0.028 & - & 0.078 & 0.014 \\
\hline CRM & $\mathrm{Ni}$ & $\mathrm{Cu}$ & $\mathrm{Zn}$ & $\mathrm{Ag}$ & $\mathrm{Sn}$ & $\mathrm{Pb}$ \\
\hline 61XMGP2 & 0.0029 & 0.0109 & 0.0122 & 0.003 & 0.0073 & 0.0061 \\
61XMGP6 & 0.0025 & 0.0067 & 0.01 & 0.0043 & 0.0091 & 0.012 \\
65XMGA15 & 0.0026 & 0.0273 & 0.348 & 0.03 & 0.0021 & 0.0051 \\
65XMGA16 & 0.0057 & 0.099 & 4.03 & 0.0035 & 0.028 & 0.050 \\
65XMGA21 & 0.001 & 0.002 & 5.11 & - & 0.0063 & 0.0048 \\
\hline
\end{tabular}

a. Balance values, 100 - sum of other elements (mass\%).

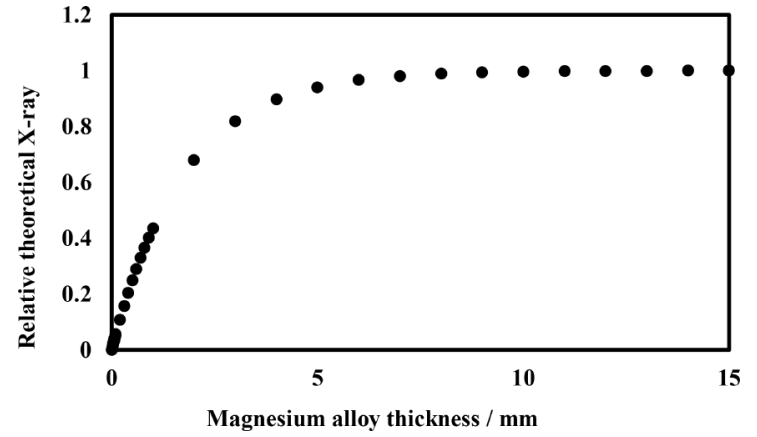

Fig. 1 Relationship between the X-ray intensity of Sn $K \alpha$ and the thickness of magnesium alloy ( 1 mass\% of $\mathrm{Sn}$ in $\mathrm{Mg}$ ) calculated by the FP method.

samples were analyzed.

The quantitative values using calibration curves were also calculated by normalizing the sum of all concentrations to 100 mass \%, too, for comparing with the FP method values.

\section{Results and Discussion}

Analyzing depth and thickness of samples

The XRF intensity depends on not only the sample composition, but also on the thickness. When the sample thickness increases to a certain level, the X-ray intensity becomes saturated. This is referred to as "bulk thickness". ${ }^{27}$

Previous knowledge concerning the required bulk thicknesses for all analyzed X-ray lines is important for XRF quantification. The bulk thickness can be calculated by the Lambert-Beer law using the sample composition and a mass absorption coefficient. Therefore, theoretical X-ray intensities take into account any absorption and enhancement effects, which were calculated precisely by the FP method for the bulk thickness required for $\mathrm{XRF}$ of magnesium alloys. The fluorescent X-rays used in this calculation were $\mathrm{Sn} K \alpha(0.049 \mathrm{~nm})$, which has the shortest wavelength of the 12 analytical elements. The theoretical X-ray intensities were calculated with an imaginary sample composed of $\mathrm{Mg} 99 \mathrm{mass} \%$ and $\mathrm{Sn} 1 \mathrm{mass} \%$. Figure 1 shows the relationship between the X-ray intensities of Sn $K \alpha$ emitted from the sample calculated by the FP method for primary X-rays from a Rh target and the thickness of the sample. The X-ray
Table 3 Estimated analyzing depth corresponding to the $99 \%$ saturated of X-ray intensities of 12 elements in magnesium ingots and alloys calculated by the FP method

\begin{tabular}{llcl}
\hline Element & $\begin{array}{c}\text { Analytical } \\
\text { line }\end{array}$ & $\begin{array}{c}\text { Wavelength/ } \\
\mathrm{nm}\end{array}$ & $\begin{array}{c}\text { Analyzing depth/ } \\
\mathrm{mm}\end{array}$ \\
\hline $\mathrm{Mg}$ & $K \alpha$ & 0.99 & 0.02 \\
$\mathrm{Al}$ & $K \alpha$ & 0.83 & 0.003 \\
$\mathrm{Si}$ & $K \alpha$ & 0.71 & 0.005 \\
$\mathrm{Ca}$ & $K \alpha$ & 0.34 & 0.04 \\
$\mathrm{Mn}$ & $K \alpha$ & 0.21 & 0.1 \\
$\mathrm{Fe}$ & $K \alpha$ & 0.19 & 0.2 \\
$\mathrm{Ni}$ & $K \alpha$ & 0.17 & 0.3 \\
$\mathrm{Cu}$ & $K \alpha$ & 0.15 & 0.4 \\
$\mathrm{Zn}$ & $K \alpha$ & 0.14 & 0.4 \\
$\mathrm{Ag}$ & $K \alpha$ & 0.06 & 7 \\
$\mathrm{Sn}$ & $K \alpha$ & 0.05 & 9 \\
$\mathrm{~Pb}$ & $L \beta_{1}$ & 0.10 & 1 \\
\hline
\end{tabular}

intensity of $\mathrm{Sn} K \alpha$ reached saturation when the sample thickness was $10 \mathrm{~mm}$ or larger. Table 3 shows the X-ray analyzing depths of the 12 elements. These were calculated as being $99 \%$ saturated X-ray intensities with the imaginary sample composition of $\mathrm{Mg} 99.89$ mass\% and 11 elements 0.01 mass\%. As can be seen from Table 3, the analyzing depths of the 11 elements (excluding $\mathrm{Sn}$ ) are less than or equal to $7 \mathrm{~mm}$. Even the analyzing depth of $\mathrm{Sn} K \alpha$ is about $9 \mathrm{~mm}$. The thicknesses of the samples used in this study were $10 \mathrm{~mm}$ or larger, where they can be considered to have bulk thickness.

\section{Polishing the surface of $\mathrm{Mg}$ alloys}

When analyzing solid samples by XRF, the analytical surfaces are often polished so as to avoid any effects of surface irregularities and to remove surface contamination. Exposing magnesium ingots and alloys to the air atmosphere causes an oxide film to form on the sample surface. ${ }^{28}$ Since oxide film influences the analytical results, the sample surfaces were polished before being measured. ${ }^{6}$ The surface layer oxygen absorbs fluorescent $\mathrm{X}$-rays of light elements, such as $\mathrm{Mg}$ and $\mathrm{Al}$, and may reduce their intensities significantly. Therefore, the time-dependent change of the fluorescent X-ray intensities due to surface oxidation was investigated. After polishing a magnesium ingot $(\mathrm{Mg}-\mathrm{A})$, the fluorescent $\mathrm{X}$-ray intensities of $\mathrm{Mg} K \alpha$ and $\mathrm{O} K \alpha$ were measured every other hour for $24 \mathrm{~h}$. Figure 2 shows the changes in the fluorescent X-ray intensities 
of these two lines. An evaluation of changes in the fluorescent $\mathrm{X}$-ray intensity was carried out to compare with the value of 3 -times the standard deviation of the fluorescent X-ray intensity obtained with a statistic error $\left(3 \sigma_{\text {cal. }}\right)$. The range of $\pm 3 \sigma_{\text {cal. }}$ is indicated as the broken line in Fig. 2. When measured for $24 \mathrm{~h}$, the $\mathrm{Mg} K \alpha$ and $\mathrm{O} K \alpha$ intensities were both within $\pm 3 \sigma_{\text {cal. }}$. From these results, it can be concluded that there is no problem in the analysis of $\mathrm{Mg}$ with $\mathrm{XRF}$, although there is a possibility that surface oxidation occurs.

When the sample surface is polished, the fluorescent X-ray intensity may change due to contamination by the abrasive and the surface condition after polishing. In particular, the X-ray intensity of $\mathrm{Mg} K \alpha$ which has a long wavelength, may decrease

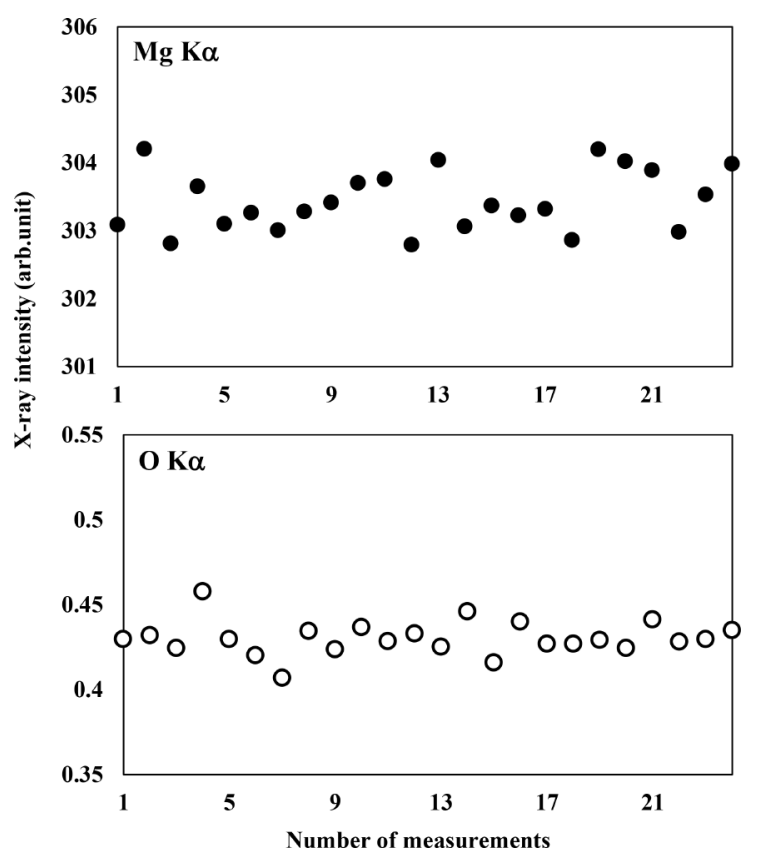

Fig. 2 Variations in the X-ray intensities of $M g K \alpha(\bullet)$ and $\mathrm{O} K \alpha$ (○) generated from a magnesium metal with the irradiation time of the primary X-ray from the $\mathrm{Rh} X$-ray tube operated at $50 \mathrm{kV}$ and $60 \mathrm{~mA}$. Broken line, intervals of statistic error $\left(3 \sigma_{\text {cal. }}\right)$ of $\mathrm{X}$-ray measurements. due to variations in the surface roughness and, because aluminum is the major component in alumina abrasive paper, the X-ray intensity of $\mathrm{Al} K \alpha$ may increase. Therefore, an experiment was performed to determine whether polishing affected these X-ray intensities. $\mathrm{Mg} K \alpha$ and $\mathrm{Al} K \alpha$ for the unknown sample Mg-B (AM60B) were measured immediately after polishing. This operation was performed 5 times. The resulting the relative standard deviation of the $\mathrm{Mg} K \alpha$ intensity was $0.22 \%$, which was equivalent to the statistical fluctuation. Consequently, it can be concluded that the variation in the X-ray intensity due to polishing can be disregarded. Similarly, the relative standard deviation of the $\mathrm{Al} K \alpha$ intensity was $0.55 \%$, which indicated that contamination from the alumina abrasive paper was negligibly small.

\section{Evaluation of the analytical results}

In order to confirm that the analytical values obtained from the standardless FP method compared favorably to those obtained from the conventional calibration curves method, samples Mg-A, B and C were analyzed by the FP method and the calibration curves methods (Table 4). For all three unknown samples, the quantitative values by the standardless FP method were consistent with the analytical values obtained by the calibration curve method. The relative standard deviation of analytical values with 10-times repetition had acceptable precisions $(10 \%$ levels) for the elements of low concentration (10 mass ppm (mg/kg)) in XRF analysis. To confirm the accuracy of the analytical values by the proposed standardless FP method, 12 elements in 5 types of certified reference materials were quantified by this method, and the relationship between the quantitative values and the certified values were evaluated by the orthogonal regression method (Fig. 3). The "accuracy" equation $^{29}(1)$ was used to evaluate how well the analysis values matched the certified values.

$$
\text { Accuracy }(\operatorname{mass} \%)=\sqrt{\frac{\sum\left(C_{\mathrm{i}}-W_{\mathrm{i}}\right)^{2}}{n-m}}
$$

This equation is the residual sum of squares of the analysis and certified values, where $C_{\mathrm{i}}$ is the certified value (mass\% or ppm), $W_{\mathrm{i}}$ is the analysis value (mass\% or ppm), $n$ is the number of samples (5 CRMs) and $m$ is the degree of freedom. In this case, the degree of freedom, $m$, is zero because only the certified

Table 4 Analytical results of 12 elements in a magnesium ingot (Mg-A) and 2 magnesium alloys (Mg-B and Mg-C) by standardless FP method in comparison with conventional calibration curve method

\begin{tabular}{|c|c|c|c|c|c|c|}
\hline \multirow{2}{*}{$\begin{array}{l}\text { Sample } \\
\text { Element }\end{array}$} & \multicolumn{2}{|c|}{$\mathrm{Mg}-\mathrm{A}$} & \multicolumn{2}{|c|}{$\mathrm{Mg}-\mathrm{B}$} & \multicolumn{2}{|c|}{$\mathrm{Mg}-\mathrm{C}$} \\
\hline & $\mathrm{FP}^{\mathrm{a}}$ & Calibration $^{\mathrm{b}}$ & $\mathrm{FP}^{\mathrm{a}}$ & Calibration $^{\mathrm{b}}$ & $\mathrm{FP}^{\mathrm{a}}$ & Calibration $^{\mathrm{b}}$ \\
\hline $\mathrm{Mg}$ & $99.95(0.0)$ & $99.97(0.1)$ & $93.82(0.0)$ & $93.89(0.1)$ & $89.22(0.0)$ & $89.29(0.1)$ \\
\hline $\mathrm{Al}$ & $0.005(9.4)$ & $0.005(9.0)$ & $5.71(0.1)$ & $5.69(0.1)$ & $9.99(0.1)$ & $10.06(0.1)$ \\
\hline $\mathrm{Si}$ & $0.020(2.5)$ & $0.013(2.5)$ & $0.120(0.8)$ & $0.08(0.8)$ & $0.059(1.4)$ & $0.040(1.4)$ \\
\hline $\mathrm{Ca}$ & N.D. & N.D. & N.D. & N.D. & N.D. & N.D. \\
\hline $\mathrm{Mn}$ & $0.012(2.7)$ & $0.009(3.8)$ & $0.270(0.3)$ & $0.27(0.3)$ & $0.143(0.7)$ & $0.0141(0.8)$ \\
\hline $\mathrm{Fe}$ & $0.0026(4.0)$ & $0.0031(3.4)$ & $0.0029(4.0)$ & $0.0036(3.0)$ & $0.0087(2.0)$ & 0.0091 (1.6) \\
\hline $\mathrm{Ni}$ & $0.0006(11.0)$ & N.D. & $0.0014(6.6)$ & $0.0009(10.2)$ & $0.0015(6.5)$ & $0.0010(10.5)$ \\
\hline $\mathrm{Cu}$ & $0.0006(14.4)$ & N.D. & $0.0070(1.0)$ & $0.0070(1.4)$ & $0.0154(0.6)$ & $0.0157(0.8)$ \\
\hline $\mathrm{Zn}$ & $0.0023(5.7)$ & $0.0022(5.9)$ & $0.046(0.9)$ & $0.047(0.9)$ & $0.559(0.3)$ & $0.559(0.3)$ \\
\hline $\mathrm{Ag}$ & N.D. & N.D. & N.D. & N.D. & N.D. & N.D. \\
\hline Sn & N.D. & N.D. & $0.0056(6.8)$ & $0.0050(7.3)$ & $0.0021(13.0)$ & $0.0014(17.8)$ \\
\hline $\mathrm{Pb}$ & N.D. & N.D. & $0.0056(1.3)$ & $0.0060(1.5)$ & $0.0020(3.4)$ & $0.0023(3.5)$ \\
\hline
\end{tabular}

a. Standardless FP method. b. Calibration curve method by using 5 certified reference materials of magnesium ingots and magnesium alloys. ( ): Relative standard deviation in \%, $(n=10)$, N.D.: not detected. 

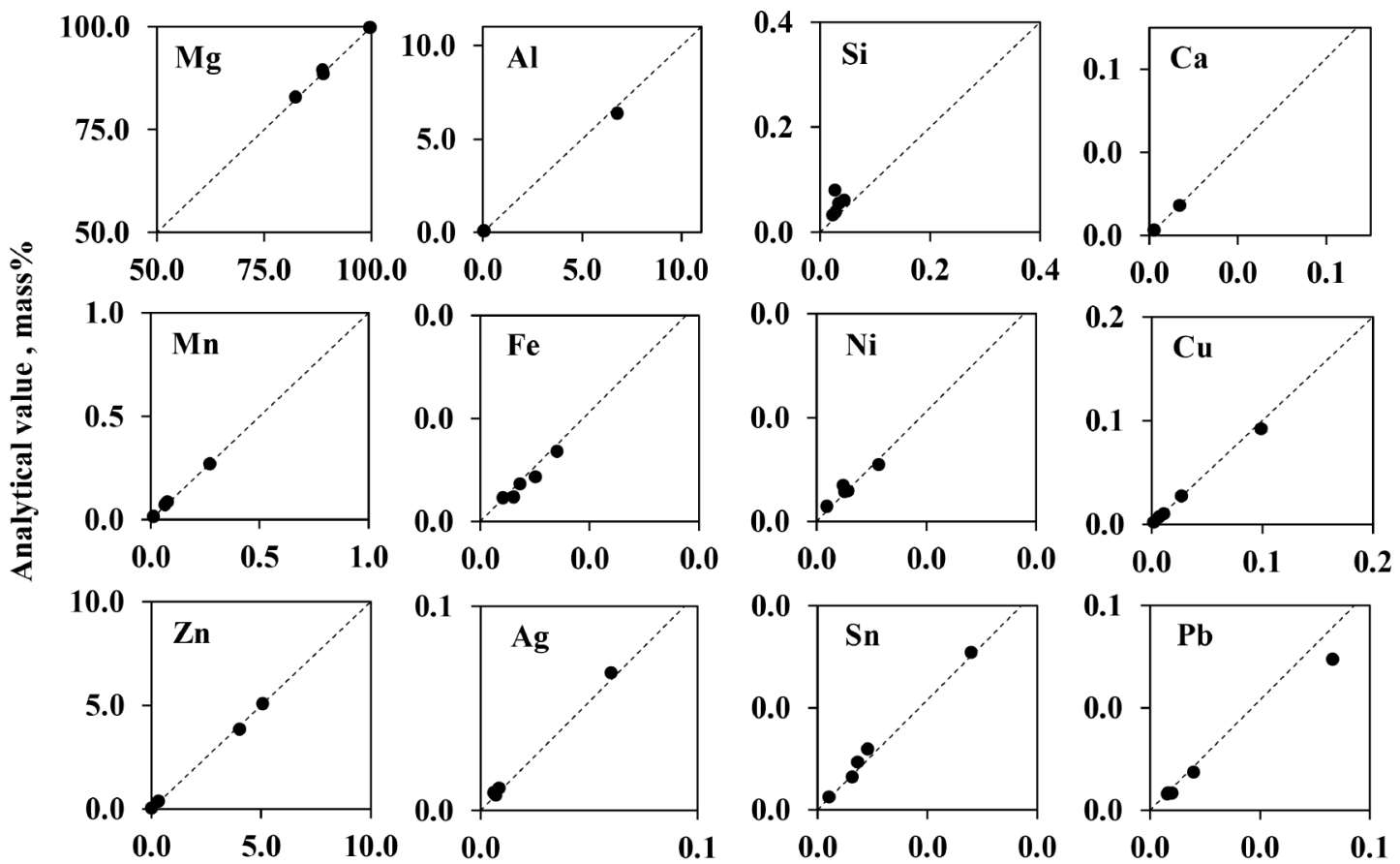

Certified value, $\operatorname{mass} \%$

Fig. 3 Orthogonal regression analysis of analytical values by FP-XRF and certified values of 2 magnesium ingots standards* and 3 magnesium alloys standards**. Broken lines are shown in the case of the correlation parameter is 1. *: MBH Analytical 61X MGP2 (Mg ingot) and 61X MGP6 (Mg ingot). **: MBH Analytical 65XMGA15 (Mg-Al-Zn alloys), 65XMGA16 (Mg-Al-Zn alloys) and 65XMGA21 (AZ125 alloys).

Table 5 Accuracy of 12 elements in a magnesium alloys (unit: mass\%)

\begin{tabular}{lcccc}
\hline Element & $\mathrm{Mg}$ & $\mathrm{Al}$ & $\mathrm{Si}$ & $\mathrm{Ca}$ \\
Range & $82.39-99.82$ & $0.04-12.37$ & $0.02-0.04$ & 0.03 \\
Accuracy & 0.4 & 0.3 & $\mathrm{Ni}$ & $0.0024-0.0139$ \\
\hline Element & $\mathrm{Mn}$ & $\mathrm{Fe}$ & 0.003 \\
Range & $0.0118-0.2710$ & $0.0041-0.0140$ & $0.0010-0.0057$ & $0.0020-0.0990$ \\
Accuracy & 0.004 & 0.0009 & 0.0005 & 0.003 \\
\hline Element & $\mathrm{Zn}$ & $\mathrm{Ag}$ & $\mathrm{Sn}$ & $\mathrm{Pb}$ \\
Range & $0.01-5.11$ & $0.0030-0.0300$ & $0.0021-0.0280$ & $0.0048-0.0500$ \\
Accuracy & 0.09 & 0.002 & 0.002 & 0.003 \\
\hline
\end{tabular}

value and the analysis value are compared. The accuracy values are listed in Table 5 .

The accuracy for $\mathrm{Mg}$ (concentration range of $82.39-99.82$ mass \%) was $0.36 \times$ mass $\%$. Highly accurate results were also obtained for the added components. For example, $\mathrm{Al}$ (range of $0.04-12.37$ mass $\%$ ) was 0.3 mass $\%$, $\mathrm{Zn}$ (range of $0.11-$ 5.11 mass\%) was 0.09 mass\% and Mn (range of $0.0118-$ 0.2710 mass \%) was 0.004 mass $\%$. The accuracy results of the impurity components (low concentration range) were also high: for example, $\mathrm{Fe}$ (range of $41-140$ mass ppm) was $9 \mathrm{ppm}, \mathrm{Ni}$ (range of $10-57$ mass ppm) was $5 \mathrm{ppm}$ and $\mathrm{Cu}$ (range of 20 990 mass ppm) was $30 \mathrm{ppm}$. These accuracies were good for dynamic concentration range. However, the accuracy result of $\mathrm{Si}$ was 0.03 mass\% (correlation factor $r$ of 0.757 ), which was significantly less than that of the other elements, because $\mathrm{Si}$ exists as $\mathrm{Mg}_{2} \mathrm{Si}$ in magnesium alloys non-uniformly without dissolving in the alloys. ${ }^{30}$ Consequently, it was confirmed that the analysis of magnesium ingots and alloys using the standardless FP method proposed in this paper is an analytical method of high quantitative accuracy.

\section{Conclusions}

The total analysis of various magnesium alloy components was studied by XRF using the standardless FP method without type standards:

(1) $10 \mathrm{~mm}$ thickness for the samples is appropriate for XRF analysis.

(2) The fluorescent X-rays intensities of the analytical elements were neither affected by surface oxidation in air or by vacuum atmospheres and contamination due to polishing. Polishing reproducibility was also satisfactory with relative standard deviations of less than $1 \%$. 
(3) The analytical values obtained by the standardless FP method were comparable to those obtained by the conventional calibration curves method. The relative precisions were less than $10 \%$ for trace elements $(10$ ppm), and good results were obtained.

(4) The analytical values obtained by the proposed method were highly consistent with the values of the main component $(\mathrm{Mg})$ to trace elements $(\mathrm{Fe})$ with respect to the certified values of the reference materials.

\section{References}

1. A. Yoshida, "The Japan Magnesium Association", 2011, Maruzen Shuppan, Tokyo, 20.

2. Magnesiumu.or.jp, http://magnesium.or.jp/_wp/wp content/ uploads/2018/04/, accessed on 2019/4/15.

3. S. Sandlöbes S. Zaefferer, I. Schestakow, S. Yi, and R. Gonzalez-Martinez, Acta Mater., 2011, 59, 429.

4. H. Somekawa, Y. Osawa, A. Singh, K. Washio, A. Kato, and T. Mukai, Mater. Trans., 2014, 55, 182.

5. J. H. Greenblatt, J. Appl. Chem., 1959, 9, 401.

6. JIS H 1322, "Magnesium and Magnesium Alloys-Method for Spark Discharge Atomic Emission Spectrometric Analysis", 2017, Japanese Industrial Standards Committee, Tokyo.

7. JIS H 1332, "Methods for Determination of Aluminium in Magnesium and Magnesium Alloys", 1999, Japanese Industrial Standards Committee, Tokyo.

8. JIS H 1333, "Methods for Determination of Zinc in Magnesium and Magnesium Alloys", 1999, Japanese Industrial Standards Committee, Tokyo.

9. JIS H 1334, "Methods for Determination of Manganese in Magnesium and Magnesium Alloys", 1999, Japanese Industrial Standards Committee, Tokyo.

10. JIS H 1335, "Methods for Determination of Silicon in Magnesium and Magnesium Alloys", 1998, Japanese Industrial Standards Committee, Tokyo.

11. JIS H 1336, "Methods for Determination of Copper in Magnesium and Magnesium Alloys", 1999, Japanese Industrial Standards Committee, Tokyo.

12. JIS H 1337, "Methods for Determination of Nickel in Magnesium and Magnesium Alloys", 1999, Japanese Industrial Standards Committee, Tokyo.

13. JIS H 1338, "Methods for Determination of Iron in Magnesium and Magnesium Alloys", 1999, Japanese Industrial Standards Committee, Tokyo.
14. JIS H 1339, "Methods for Determination of Beryllium in Magnesium and Magnesium Alloys", 2010, Japanese Industrial Standards Committee, Tokyo.

15. JIS H 1340, "Methods for Determination of Zirconium in Magnesium and Magnesium Alloys", 1998, Japanese Industrial Standards Committee, Tokyo.

16. JIS H 1341, "Methods for Determination of Calcium in Magnesium and Magnesium Alloys", 1990, Japanese Industrial Standards Committee, Tokyo.

17. JIS H 1342, "Methods for Determination of Tin in Magnesium and Magnesium Alloys", 2008, Japanese Industrial Standards Committee, Tokyo.

18. JIS H 1343, "Methods for Determination of Lead in Magnesium and Magnesium Alloys", 2008, Japanese Industrial Standards Committee, Tokyo.

19. JIS H 1344, "Methods for Determination of Cadmium in Magnesium and Magnesium Alloys", 2010, Japanese Industrial Standards Committee, Tokyo.

20. JIS H 1345, "Methods for Determination of Rare Earth in Magnesium and Magnesium Alloys", 1998, Japanese Industrial Standards Committee, Tokyo.

21. ALCOA: LGC Standards.com, https://www.lgcstandards. com/IT/en/Industry-Insights/Metal-Alloy-Standards-andCRMs/Other-Non-Ferrous-Metals/Magnesium-Base/ALCOAMagnesium-Base/cat/252321\#, 2019/1/23.

22. BAS: LGC Standards.com, https://www.lgcstandards.com/ IT/en/Industry-Insights/Metal-Alloy-Standards-and-CRMs/ Other-Non-Ferrous-Metals/Magnesium-Base/BAS-MagnesiumBase/cat/266606, 2019/1/23.

23. MBH Analytical: "MBH Reference Materials", http://mbh co.uk/products/metals/, accessed on 2019/1/23.

24. JIS G 1256, "Iron and Steel-Method for X-ray Fluorescence Spectrometric Analysis", 2013, Japanese Industrial Standards Committee, Tokyo.

25. JIS R 2216, "Methods for X-ray Fluorescence Spectrometric Analysis of Refractory Products" 2005, Japanese Industrial Standards Committee, Tokyo.

26. T. Siraiwa and N. Fujino, Japanese Journal Applied Physics, 1966, 5,886

27. H. Takahara, "X-ray Spectroscopy", ed. K. Tsuji and Y. Muramatsu, 2018, Kodansya, Tokyo, 79 - 83 (in Japanese).

28. J. H. Nordlien, S. Ono, N. Masuko, and K. Nisanciogle, Corros. Sci., 1997, 39, 1397.

29. Y. Watanabe, Y. Kurita, Y. Ono, M. Takada, S. Nakai, and M. Hosomi, J. Environ. Chem., 2005, 15, 145.

30. H. Oginuma, K. Kondoh, M. Sumida, and E. Yuasa, J. Jpn. Powder Metallurgy, 2005, 52, 282. 